\title{
CINEMA E LITERATURA COMO INSTRUMENTOS DE CONTENÇÃO DA CRISE OPERACIONAL DO ENSINO JURÍDICO
}

\section{CINEMA AND LITERATURE AS INSTRUMENTS OF CONTAINMENT OF THE OPERATIONAL CRISIS OF LEGAL EDUCATION}

\section{${ }^{1}$ Fernando da Silva Mattos}

${ }^{2}$ Thais Luzia Colaço

\section{RESUMO}

A constatação de que o ensino jurídico se encontra permeado de crises, conduz os juristas a procurar soluções para que estas sejam atenuadas. Entre as crises que atingem os Cursos de Direito o presente artigo trata da relacionada ao seu aspecto operacional, notadamente no que tange aos métodos didático-pedagógicos. Apresenta-se co22mo instrumentos de contenção da crise operacional o Cinema e a Literatura, com destaque especial ao fato de que tais manifestações artísticas têm a possibilidade de sensibilizar os alunos para questões da cotidianidade, do outro, pela via da empatia.

Palavras-Chave: Ensino jurídico; crise operacional; Direito e Arte; Direito e Cinema; Direito e Literatura.

\begin{abstract}
Noting that the legal education is riddled with crisis leads jurists to seek solutions for mitigation. Among the crisis that strike the Courses of Law, this article deals with the operational aspect, particularly, regards about didactic and pedagogical methods. It is presented as contantion instruments of operational crisis, the Cinema and the Literature, with special attention to the fact that these artistic expressions have the opportunity to sensitize students to the issues of everyday life, to look the other, through the way of empathy.
\end{abstract}

Key-Words: Legal education; Operational Crisis; Law and Art; Law and Cinema; Law and Literature.

\footnotetext{
${ }^{1}$ Doutorando em Direito pela Universidade Federal de Santa Catarina - UFSC, Santa Catarina (Brasil). E-mail: fsmattos@live.com

${ }^{2}$ Doutora em Direito pela Universidade Federal de Santa Catarina - UFSC, Santa Catarina (Brasil). Professora da Universidade do Extremo Sul Catarinense - UNESC, Santa Catarina (Brasil). E-mail: thais@ccj.ufsc.br
} 


\section{INTRODUÇÃO}

O ensino do direito está em crise! A mencionada afirmação tornou-se comum tanto na academia como entre os operadores do Direito. Diz-se que tal fenômeno ocorre em virtude de diversos fatores e em meio a diversas outras crises que atingem a contemporaneidade. Algumas soluções são apresentadas, como necessidade de melhor formação humanística, ética, mais interdisciplinaridade, melhor formação profissional, utilização de métodos não tradicionais de ensino-aprendizagem etc. Entre as alternativas possíveis para superação da mencionada crise, o presente artigo - por meio de revisão bibliográfica - focará em uma delas, qual seja, a aproximação entre o direito e a arte, notadamente o Cinema e a Literatura. Para tanto, serão apresentadas algumas considerações acerca das características que revestem a crise do ensino jurídico; apontamentos sobre o método de ensino-aprendizagem tradicional e, por fim, será analisada a possibilidade de aproximação entre o Direito, o Cinema e a Literatura como um dos caminhos possíveis para atenuação ou contenção da crise.

\section{POLICRISE E A CRISE OPERACIONAL DO ENSINO JURÍDICO}

A pós-modernidade está em crise! Não há dúvida que o momento contemporâneo se caracteriza por um estado de crise em diversos âmbitos, como político, ambiental, ético, epistemológico, econômico etc. É o que Edgar Morin denomina de "policrise", pois, segundo afirma (2011a, p.93-94):

[...] não se poderia destacar um problema número um, que subordina todos os demais, não há um único problema vital, mas vários problemas vitais, e é essa intersolidariedade complexa dos problemas, antagonismos, crises, processo descontrolado, crise geral do planeta, que constitui o problema vital número um.

O ensino jurídico, como importante componente da vida em sociedade, não fica fora desse contexto de policrise. Horácio Wanderlei Rodrigues, em sua obra "Pensando o Ensino do Direito no Século XXI" enumera as diversas crises que atingem o ensino jurídico. A primeira delas é a que denomina "crise estrutural", que compreende "[...] sua estrutura axiológica. Essa coloca-se em nível dos paradigmas político-ideológico e o outro epistemológico" (RODRIGUES, 2005, p.35). Há também a “crise funcional”, que é: 
formadora de mão-de-obra qualificada para o desempenho de determinadas tarefas profissionais (RODRIGUES, 2005, p.45).

Divide-se a crise funcional em "crise do mercado de trabalho" e "crise de identidade e legitimidade dos operadores jurídicos" (RODRIGUES, 2005, p.45-49). Por fim, pode-se falar em crise operacional, que trata:

[...] do conjunto dos problemas referentes aos paradigmas administrativo, didáticopedagógico e curricular. Todos esses aspectos dizem respeito diretamente à operacionalização concreta desses paradigmas. São instrumentos adequados à reprodução dos valores presentes na sua estrutura axiológica (RODRIGUES, 2005, p.49).

A crise operacional subdivide-se em crise administrativa, didático-pedagógica e curricular. Para os fins do presente trabalho interessa especialmente à segunda. Com efeito, o Direito foi sendo construído ao longo de sua história como sendo possibilitador de promissora carreira profissional. E com essa ideia angariou novos cursos, alunos, professores, gerando a produção de livros, manuais, apostilas, resumos e cursinhos. O ensino do direito adaptou-se ao sistema capitalista de mercado, adquirindo, assim, todas as vicissitudes a ele inerentes. O resultado não poderia ser diferente daquele vivenciado por todos os demais fenômenos componentes do sistema capitalista, qual seja, crise.

Com a disseminação de cursos de Direito em ritmo acelerado, a sua qualidade foi reduzida na mesma velocidade. Prova disso é o baixo índice de aprovação no Exame de Ordem, promovido pela Ordem dos Advogados do Brasil, que visa aferir conhecimentos mínimos para quem procura exercer a mais clássica das carreiras jurídicas, qual seja a advocacia. Não se desconhece as falhas de tal exame, mas o alto índice de reprovação não deixa de ser um dado a mais a referendar as percepções que os juristas possuem acerca da má-qualidade dos cursos de Direito.

O conteúdo dos cursos jurídicos, como regra, possui alto viés positivista, vinculado ao estudo das normas, doutrina e jurisprudência, tornando o ambiente acadêmico quase impenetrável por outras ciências e outras manifestações humanas. Mesmo quando presentes na grade curricular, matérias como sociologia, filosofia, antropologia e psicologia, quando não optativas, possuem conteúdos pouco abrangentes e são pouco atraentes para os alunos, que a realizam, nos mais das vezes, somente tendo em conta sua imprescindibilidade para o término do curso e posterior colação de grau. A monografia é vista por boa parte dos alunos como mais um obstáculo a ser transposto; uma barreira desgastante que somente tem o condão de atrapalhar 
estudos mais intensivos para os exames e concursos que se aproximam com o término do curso (RODRIGUES, 2005).

Tudo isso leva à compreensão do porquê de o método denominado "coimbrão" ser tão comum no campo da educação jurídica. Ele é estruturado sobre aulas expositivas, centradas no professor, entendendo que o aluno apenas analisará o conteúdo munido de toda a fundamentação teórica passada em aula. Tal compreensão do ensino como transmissão de informações desconsidera as diferenças entre os alunos, todos convertidos em tabula rasa, iguais em sua ignorância acadêmica, impondo reflexos na avaliação e no material utilizado. Este último privilegia textos, manuais, slides, tudo que possa resumir os conceitos considerados importantes pelo professor, sem maiores problematizações. Por sua vez, a avaliação concentrase em provas dissertativas finais e mede o acumulo de conhecimento do aluno. Ghirardi (2012) entende que esse tipo de ensino possui qualidades, tal como o fornecimento de um repertório teórico para os discentes. O que é questionada é a sua eficiência.

Os professores, assoberbados com suas outras atividades profissionais ou, quando em dedicação exclusiva, com preparação de aulas, orientações, leituras, atualização constante, reuniões, eventos, redação de artigos, livros e outros trabalhos, pouco tempo possuem para repensar técnicas de ensino-aprendizagem que se afastem do método expositivo tradicional. Nesse sentido, críticas contundentes são realizadas à Universidade, afirmando-se que ela é um espaço tomado pelo produtivismo, pelo fazer quantitativo - a tal ponto que se valoriza ações que tenham maior número de inscritos, ou de citações na imprensa ou na obra de outros pesquisadores. Essa necessidade imposta pela burocratização e que impõe, por exemplo, a indicação em relatórios de todas as citações que a obra escrita pelo professor recebeu, retira-lhe tempo precioso de seu verdadeiro trabalho (de ensino, gestão científica e pesquisa). As exigências de revistas e avaliadores passam a definir o que se escreve: "Grão a grão, a brisa fresca no rosto que é pesquisar e ensinar (no estado normal, o estado puro) passa a pesada corveia. Nenhuma criatividade é permitida, nenhum rasgo, nenhum risco" (CUNHA, 2012, p.10).

Soma-se a isto, ainda, a pouca afinidade que muitos professores do campo jurídico possuem com mecanismos didático-pedagógicos e com a capacitação docente (COLAÇO, 2006). Enfim, o ensino do direito vem - há muito tempo - perpassado pelo que Paulo Freire denomina de "ensino bancário". Com efeito, segundo este autor, o ensino bancário caracterizase pela preponderância da passividade do aluno, que é visto como depositário dos conhecimentos que são repassados pelo professor. Afirma Freire (1987, p. 33): 
Quanto mais analisamos as relações educador-educandos, na escola, em qualquer de seus níveis (ou fora dela), parece que mais nos podemos convencer de que estas relações apresentam um caráter especial e marcante - o de serem relações fundamentalmente narradoras, dissertadoras.

Narração de conteúdos que, por isto mesmo, tendem a petrificar-se ou a fazer-se algo quase morto, sejam valores ou dimensões concretas da realidade. Narração ou dissertação que implica num sujeito - o narrador - e em objetos pacientes, ouvintes os educandos.

Há uma quase enfermidade da narração. A tônica da educação é preponderantemente esta - narrar, sempre narrar.

[...] Nela, o educador aparece como seu indiscutível agente, como o seu real sujeito, cuja tarefa indeclinável é 'encher' os educandos com conteúdos de sua narração. Conteúdos que são retalhos da realidade desconectados da totalidade em que se engendram e em cuja visão ganhariam significação. A palavra, nessas dissertações, se esvazia da dimensão concreta que devia ter ou se transforma em palavra oca, em verbosidade alienada e alienante. Daí que seja mais som que significação e, assim, melhor seria não dizê-la. Por isto mesmo é que uma das características desta educação dissertadora é a 'sonoridade' da palavra e não sua força transformadora.

\section{Conforme salienta Horácio Wanderlei Rodrigues (2005, p.52), o ensino do Direito} possui natureza preponderantemente tradicional. Afirma que na área pedagógica:

[...] o ensino do Direito apresenta-se como um dos principais focos ainda existentes, na universidade brasileira, de educação tradicional. Esse modelo tem como características gerais o primado do objeto e o privilegiamento dos modelos e do professor. Vê o aluno como receptor passivo, sendo a realidade algo que será a ele transmitido pela escola, através da educação formal. Entende que o conhecimento humano possui um caráter cumulativo, sendo a inteligência a capacidade de armazenar informações. [...] A relação professor-aluno é vertical, sendo o aluno o ouvinte e o professor o mediador entre ele e o conhecimento. $\mathrm{O}$ docente é o agente principal da relação ensino-aprendizagem. Há ênfase às situações de sala de aula, e a avaliação tem caráter eminentemente quantitativo.

Salienta ainda o mencionado doutrinador que na área didática também há a prevalência de metodologias tradicionais, sendo a opção preferencial pelos docentes a aula-conferência. Assim, segundo Rodrigues (2005, p.53):

Em grande parte, seus professores possuem uma formação pedagógica insuficiente (ou mesmo nenhuma preparação didático-pedagógica) e se restringem, em sala de aula, a expor o ponto do dia, comentar os artigos dos códigos e contar casos de sua vida profissional, adotando um ou mais livros-texto, que serão cobrados dos alunos nas verificações.

Percebe-se, portanto, que o ensino jurídico tradicional é eminentemente bancário. Os professores, como regra, realizam a leitura de obras jurídicas, sistematizando-as, para após transmitirem de forma expositiva o conteúdo lido aos alunos. Feito isso, conclui-se determinado 
conteúdo, reiniciando o processo em relação aos conteúdos subsequentes e assim até o final da disciplina (COLAÇO, 2006).

É comum a prática inclusive de se recomendar determinada(s) obra(s) jurídica(s) para os alunos, a fim de que estes acompanhem o desenrolar da disciplina. Possuem os alunos, assim, duas fontes depositárias de conhecimento, em regra, eminentemente dogmáticas e positivistas: o professor e a doutrina. A fim de dar autenticidade ao conhecimento lido previamente, não é raro que ocorra a indicação pelo professor aos alunos de uma obra jurídica que não seja base da sua leitura. Assim, os alunos leem determinado conteúdo em uma obra e têm seus conhecimentos suplementados pelo professor durante as aulas, utilizando-se, este, de obra diversa propositalmente não indicada. Roberto Lyra Junior (1988) denomina de "professor ceguinho" àquele que adota tal prática.

Ao lado do professor ceguinho, apregoa existirem ainda os catedráticos e os nefelibatas, todos componentes do que chama "docentes conservadores". Diz o autor (1988, p.42):

Estes dividem-se em três grupos principais: os ceguinhos, que servem à dominação por burrice e ignorância; os catedráticos, que a ela servem por safadeza; e os nefelibatas, que acabam fazendo a mesma coisa, por viverem nas nuvens.

Vocês os conhecem. O ceguinho é aquele que 'adota' um compêndio do tipo Maluf, para ser decorado pelos alunos, e, nas aulas, disfarça a pobreza de espírito, repetindo um outro livro, não citado, que é a "cola" do mestre. Descubram este último, e ele está no papo.

Nos meus tempos de estudante, havia um ceguinho que nos mandava rezar, nas provas, os capítulos do Direito Processual Civil, do Gabriel Rezende Filho, e salvava face recitando nas aulas os verbetes escolhidos duma enciclopédia italiana.

Os catedráticos me recordam aquele outro professor da época, que considerava "comunista" o Primeiro Ministro da Inglaterra e berrava, agitando os óculos no ar, como o Deputado Amaral Neto agita o revólver quando se fala nas eleições diretas: 'comigo é na Lei, estão ouvindo? É no Código! E quem critica a lei, a ORDEM, é CO-MU-NIS-TA! [...].

Mas há também os nefelibatas, aqueles que conhecem mil leis, mil doutrinas, mil teorias, mas nem suspeitam o que elas representam, como projeção de circunstâncias, classes, grupos em luta, no mundo real e material. E fazem uma salada semelhante á que Marx censurava Stirner, com a "ideia do Direito", que tiram da cabeça, e das leis, em lugar de vê-la em função das relações sociais. Assim, leis e doutrinas tornam-se "fantasmas", numa pseudociência de assombrações e porrinhos idealistas.

Nesse cenário caótico, como depositários dos conhecimentos transmitidos por professores ceguinhos, catedráticos ou nefelibatas, novos Bacharéis são formados a cada semestre em centenas de cursos de Direito espalhados pelo Brasil. E nesse contexto de crise operacional do ensino do Direito que devem ser pensadas novas ferramentas didáticopedagógicas possíveis de serem utilizadas para otimizar o processo de ensino-aprendizagem. É claro que alternativas concomitantes devem ser objeto de reflexão, pois problemas complexos 
não se resolvem com medidas isoladas. O importante é ter consciência da crise e da necessidade de busca de soluções, muitas vezes buscando-as nas mais variadas fontes pedagógicas,

O pluralismo de concepções pedagógicas permite ao professor eleger ferramentas para o exercício de sua profissão (métodos, metodologias, estratégias) dentre aquelas reconhecidas pela teoria educacional. Isso inclui escolhas didáticas, textuais, teóricas, por exemplo. Tudo isso no contexto do art. 205 da Constituição Federal de 1988 (CF/88) (BRASIL, 1988) que estabelece o direito de todos à educação de qualidade. O art. 209 traz a previsão constitucional de que as instituições privadas (e públicas, acrescenta-se) devem cumprir com as normas educacionais gerais - e da mesma forma, seus professores deverão adequar suas aulas e documentação exigida aos parâmetros estabelecidos nacionalmente.

Ainda que limitada por tais regramentos, a liberdade de ensinar permite às instituições de ensino que elaborem seus projetos pedagógicos desde que cumpram com o quadro geral desenhado pela federação. São garantidas, igualmente, aos professores no âmbito de sua disciplina a adesão teórica (desde que exponha as demais correntes doutrinárias) e a escolha de métodos pedagógicos, conforme antes enunciado (RODRIGUES, 2014).

Desta forma, uma das possíveis escolhas é a de uma perspectiva que parta do concreto para o abstrato, onde a experiência real é requisito para a compreensão teórica. Com isso, reconhece-se as experiências dos alunos, e o professor passa a ocupar um lugar de menor destaque em aula. A diversidade torna-se importante para a troca de experiências e a busca por soluções dos problemas práticos com fundamento na teoria. Para isso, são materiais utilizados decisões, notícias de jornal, filmes, casos - tudo que possa servir de apoio para o desenvolvimento crítico da teoria. A avaliação reflete a percepção que organiza esse ensino, geralmente solicitando a resolução de um problema ou caso concreto, auferindo tanto o conhecimento do conteúdo quanto as habilidades de ponderação e decisão, por exemplo (GHIRARDI, 2012). É sobre tais escolhas, especialmente aquelas que transitam pelo cinema e pela literatura, que se passa a expor.

\section{CINEMA E LITERATURA COMO FERRAMENTAS DO ENSINO JURÍDICO PELA VIA DA EMPATIA}

Como resultado do ensino jurídico realizado no modelo tradicional, tem-se a formação em larga escala de alunos despreparados, desmotivados, alienados, desconectados da realidade 
social e das suas injustiças e da importância da ciência jurídica como instrumento de alteração dessa realidade.

Assim, devem ser discutidas novas formas de trazer a realidade ao aluno, a fim de que sua sensibilidade em relação à cotidianidade que o cerca seja aguçada, possibilitando o estabelecimento de uma relação de empatia com questões de extrema importância para a sociedade contemporânea, como a redução das desigualdades, a proteção aos grupos que se encontram em maior vulnerabilidade social, a proteção à natureza, o combate à corrupção, a construção de valores éticos sólidos, a análise adequada do fenômeno criminógeno etc. $\mathrm{O}$ Direito deve ser repensado como mecanismo de transformação da realidade, não somente como promissora opção profissional. Conforme assevera Warat (1997, p.63): “[...] a luta pela dignidade começa na tentativa de desembaraçar o discurso docente das suas vestes sacerdotais e da competência de suas provocações".

Diante desse contexto, a arte, notadamente o cinema e a literatura, se bem utilizadas, podem ser importantes ferramentas para atenuação da crise didático-pedagógica que permeia o ensino do Direito, principalmente pelo alto poder de sensibilização que lhes caracteriza. Seria ingenuidade caracterizar a arte como panaceia para a crise do ensino jurídico. É apenas um instrumento a mais a disposição do professor.

Com efeito, durante a história da humanidade a arte exerceu o papel de auxiliar o homem a compreender e transformar a realidade em que está inserido, não exercendo funções meramente estéticas. Conforme assevera Hegel (2001, p. 57).

\begin{abstract}
A pior apreensão, a maneira menos adequada para o espírito, é a apreensão meramente sensível. Ela consiste primeiramente no meu ver,escutar, tocar e assim por diante, para muitos, constituir de modo geral um passatempo como quando se caminha ao léu sem pensar em nada e apenas se escuta algo aqui e ali, se olha para cá e para lá e assim por diante. $\mathrm{O}$ espírito não se limita à mera apreensão das coisas externas por meio da visão e do ouvido, ele as transforma para o seu interior.
\end{abstract}

A arte, assim, tem condão de ingressar nas subjetividades humanas, levando ao indivíduo sensações e sentimentos que o fazem refletir sobre a sua própria condição, da sociedade e do mundo que o cerca pela via da empatia, ou seja, pela capacidade de se identificar e compreender o mundo do outro, sem julgamentos prévios. Empatia é definida da seguinte forma (EDIPE, 1987):

Etimologicamente, "dentro da emoção", "junto com a emoção". Psicologicamente, identificação emocional da pessoa com indivíduos ou coisas percebidas. O radical da palavra empatia é pathos, termo grego com que designa a qualidade que excita a emoção. Difere da simpatia ou "união das emoções", da antipatia "oposição das 
emoções" e da apatia "ausência de emoções". Segundo conceitua um tratadista, "Empatia é a capacidade que possuímos de penetrar a personalidade alheia para obtermos uma previsão, uma antecipação, uma avaliação o mais seguro possível das suas reações. Enquanto a simpatia pode criar uma expectativa otimista e a antipatia uma previsão pessimista, constituindo ambas uma visão deformada pelo sentimento, a empatia é uma identificação psíquica”.

Dentre as manifestações artísticas mencionadas que possuem maior facilidade de utilização no ambiente escolar, cita-se primeiramente o cinema. $\mathrm{O}$ cinema possui alto poder de sensibilização e geração de empatia. Conforme ressalta Regis de Morais (2010, p.72):

Há filmes que acrescentam vida às nossas vidas, fazendo-nos rediscutir e reavaliar nossas existências de forma às vezes terapêutica; são filmes que nos mobilizam (émotion), que abrem recantos escondidos da nossa casa mental, forçando ali a entrada do ar puro e da saúde solar.

O mesmo autor salienta o alto poder de transmissão de emoções que possuem as obras cinematográficas, que conseguem transmitir com detalhes as sensações e até os pensamentos dos personagens, tudo compondo sua sofisticada linguagem (MORAIS, 2010, p.71):

\begin{abstract}
Raros são, hoje, os que se negam a ver uma sofisticada linguagem cinematográfica nascida, como observou Bernardet, da narrativa emocional e atualmente trazida, mediante recursos objetivos dramáticos que fazem avançar a narrativa e recursos subjetivos que procuram materializar o conteúdo mental dos personagens e cenas com insights psicológicos, ao nível de extraordinário refinamento - ao menos para as produções que se querem propriamente artísticas. Como bem o observa, Marcel Martin (2003, p183-95), hoje há procedimentos secundários mas nada desimportantes na narrativa cinematográfica, "jogos de cena e efeitos visuais e sonoros" que manejam o ritmo emocional da película. São sugestões de onirismo, de situações de devaneio, de vertigem e desfalecimento, como de alucinações ou mesmo de morte; frutos da criatividade dos cineastas e, às vezes, filhos dos progressos da psicologia e mesmo dos estudos em psicopatologia.
\end{abstract}

O cinema, como possuidor da capacidade de afetar os que lhe assistem, como instrumento didático, possibilita ao professor trazer filmes ou cenas históricas, sensibilizadoras, emocionantes, chocantes, reflexivas, trágicas, reais, alegres e tristes aos alunos sem sair do ambiente de uma sala de aula. Sentindo a vida refletida através do cinema, os alunos podem discutir temas relevantes e se posicionar a seu respeito, agregando mais esse componente a sua formação pessoal e educacional.

A título de ilustração, traz-se o filme "Assassinato em Primeiro Grau", que é baseado em fatos reais. O filme trata de um sujeito, Henry Young, que roubou cinco dólares do interior de uma loja a fim de comprar alimento para sua irmã. Ele é preso, condenado e encaminhado a Alcatraz, de onde tenta evadir-se, o que resulta no seu isolamento por três anos na solitária, em péssimas condições e sendo submetido à tortura reiteradamente. Nesse contexto, mata seu 
delator na frente de duzentos presos. Seu advogado realiza a sua defesa atribuindo ao tratamento recebido por Young em Alcatraz a responsabilidade pela prática do homicídio.

O filme mencionado permite a realização de diversas reflexões em sala de aula, seja numa aula de introdução ao estudo do direito, direito penal ou direito processual penal, por exemplo. Podem ser abordados diversos aspectos tratados na trama, como a criminalização de fatos cuja lesividade é baixa, as condições de aplicação do regime disciplinar diferenciado, o crime de tortura, o crime de homicídio, o estudo de provas, a sessão de julgamento no Tribunal do Júri e a responsabilidade do estado por atos praticados por seus agentes. Ou seja, um único filme, com duas horas de duração, é capaz de proporcionar a análise de diversos aspectos componentes do curso de Direito, com o diferencial da transmissão de imagens e diálogos marcados pela intenção de reprodução fiel da realidade, transportando o aluno para esta.

Em sua obra "O Direito no Cinema", Gabriel Lacerda retrata a experiência do curso de Direito da Fundação Getúlio Vargas do Rio de Janeiro, onde foi ministrada disciplina específica com o mesmo nome. Interessante reproduzir os propósitos da disciplina informados aos alunos no primeiro material impresso desta (LACERDA, 2007, p.15-16):

Busca-se com a atividade Direito no Cinema:

Sensibilizar os alunos para uma atitude diante da realidade. [...]

Ajudar os alunos a perceber qual o papel social da profissão que estão começando a aprender. (...) A experiência de trabalhar com a razão e o intelecto, sobre um material produzido primordialmente para ser percebido com a emoção, ajuda a formar a consciência dessa dualidade e a informar as escolhas.

Transmitir, compreender e fixar uma certa dose de informação básica sobre temas jurídicos. O cinema é também instrumento de informação. Prestando atenção em certos filmes é possível aprender muita coisa. A própria emoção que o cinema mobiliza suscita curiosidade e predispõe à absorção de conhecimento [...].

Exercitar capacidade de expressão, poder de síntese e habilidade de argumentação.

Pensar. Tomando conhecimento dos temas de sua profissão levados ao cinema, o estudante de direito, espera-se, será naturalmente estimulado a refletir e fazer perguntas cruciais que provavelmente já tenha feito antes: que significa ser advogado? Por que escolhi esta faculdade e não outra? É esta realmente a profissão que desejo seguir?

Na obra "Pelas lentes do Cinema: Bioética e Ética em Pesquisa", Dirce Guilhem, Debora Diniz e Fabio Zicker salientam a importância do cinema como mecanismo capaz de estimular a incorporação de valores e hábitos à sociedade e de colocar em debate questões de alta relevância social:

[...] muito do que somos tem forte fundamentação em manuais implícitos de comportamento adotados inicialmente pelos grandes ícones do cinema, em sua condição de personagens, e mais recentemente ampliados pela igualmente poderosa indústria televisiva. No início, nos espelhávamos nos modos como os galãs da era de 
ouro do cinema usavam um cigarro, por exemplo, associando-o a glamour e sedução. Atualmente, observamos o modo como as divas televisivas se comportam em cenas publicitárias de sedução amorosa, o qual interfere sobremaneira na construção de estereótipos de gênero.

Explorando um pouco mais o passado e, simultaneamente, aproximando-nos de contextos socioantropológicos relacionados às práxis narrativas do cinema, pode-se dizer que data de tempos muito recentes a mudança de estatuto das chamadas minorias no cinema mainstream. A presença de populações negras, pobres, marginalizadas e oprimidas em filmes de grande bilheteria e sem ocupar o lugar de coadjuvante ou de figuração em muito tem contribuído para a abertura do debate, em escala mundial, acerca dos direitos humanos, em especial os relativos a mulheres, a populações em situação de vulnerabilidade e à infância desprotegida.

O mesmo acontece com a literatura. Edgar Morin inclusive ressalta ser uma característica comum entre o cinema e a literatura o fato de servirem de instrumentos de reflexão sobre a condição humana. Diz o mencionado pensador: (2003, p.43-44)

[...] o romance e o cinema oferecem-nos o que é invisível nas ciências humanas; estas ocultam ou dissolvem os caracteres existenciais, subjetivos, afetivos do ser humano, que vive suas paixões, seus amores, seus ódios, seus envolvimentos, seus delírios, suas felicidades, suas infelicidades, com boa e má sorte, enganos, traições, imprevistos, destino, fatalidade...

São o romance e o filme que põem à mostra as relações do ser humano com o outro, com a sociedade, com o mundo. O romance do século XIX e o cinema do século XX transportam-nos para dentro da História e pelos continentes, para dentro das guerras e da paz. E o milagre de um grande romance, como de um grande filme, é revelar a universalidade da condição humana, ao mergulhar na singularidade de destinos individuais localizados no tempo e no espaço.

Em relação à literatura interessante análise foi realizada por Lynn Hunt no seu livro “A Invenção dos Direitos Humanos". Defende a mencionada autora que a leitura de romances exerceu importante papel na história da humanidade, contribuindo inclusive para a construção do conceito de Direitos Humanos, pela via da empatia. Segundo Hunt (2009, p.35, 38-39):

Um ano antes de publicar $O$ Contrato Social, Rousseau ganhou atenção internacional com um romance de sucesso, Júlia ou A nova Heloísa (1761). Embora os leitores modernos achem que a forma do romance epistolar ou em cartas tem às vezes um desenvolvimento torturantemente lento, os leitores do século XVIII reagiram de modo visceral. [...]

A leitura de Júlia predispôs os seus leitores para uma nova forma de empatia. Embora Rousseau tenha feito circular o termo "direitos humanos", esse não é o tema principal do romance, que gira em torno de paixão, amor e virtude. Ainda assim, Júlia encorajava uma identificação extremamente intensa com os personagens e com isso tornava os leitores capazes de sentir empatia além das fronteiras de classe, sexo e nação. Os leitores do século XVIII, como as pessoas antes deles, sentiam empatia por aqueles que lhes eram próximos e por aqueles que eram muito obviamente seus semelhantes - as suas famílias imediatas, os seus parentes, as pessoas de sua paróquia, os seus iguais sociais costumeiros em geral. [...]

Romances como Júlia levavam os leitores a se identificar com personagens comuns, que lhes eram por definição pessoalmente desconhecidos. Os leitores sentiam empatia pelos personagens, especialmente pela heroína ou pelo herói, graças aos mecanismos 
da própria forma narrativa. Por meio da troca fictícia de cartas, em outras palavras, os romances epistolares ensinavam a seus leitores nada menos que uma nova psicologia e nesse processo estabeleciam os fundamentos para uma nova ordem política e social. Os romances tornavam a Júlia da classe média e até criados como Pamela, a heroína do romance de mesmo nome escrito por Samuel Richardson, igual e mesmo superior a homens ricos como o sr. B., o empregador e futuro sedutor de Pamela. Os romances apresentavam a ideia de que todas as pessoas são fundamentalmente semelhantes por causa de seus sentimentos íntimos, e muitos romances mostravam em particular o desejo de autonomia. Dessa forma, a leitura dos romances criava um senso de igualdade e empatia por meio do envolvimento apaixonado com a narrativa. Seria coincidência que os três maiores romances de identificação psicológica do século XVIII - Pamela (1740) e Clarissa (1747-8), de Richardson, e Júlia (1761), de Rousseau - tenham sido todos publicados no período que imediatamente precedeu o surgimento do conceito dos "direitos do homem"?

Ou seja, para a autora, a força da empatia existente entre os leitores e as narrativas constantes nos romances, não pode ser desconsiderada como algo que efetivamente tenha influenciado importantes conquistas referentes aos Direitos Humanos. A proximidade que a leitura de romances cria com pessoas não pertencentes à cotidianidade do leitor, possibilita a este entender com maior propriedade as suas características, suas fragilidades, seus sentimentos, suas expectativas, suas carências e suas necessidades. Da mesma forma que contribuiu de forma tão expressiva para sensibilização política num período tão importante para consagração de direitos do homem, certamente poderá também contribuir para a sensibilização dos alunos acerca de temas hodiernamente relevantes.

Germano Schwartz ressalta essa característica da literatura de possibilitar ao leitor colocar-se no lugar do outro:

[...] também é o colocar-se no lugar do outro, o que motiva o estudo da Literatura aplicada ao Direito, pois ela possui essa habilidade, por intermédio de suas narrativas e seus personagens, de enviar o leitor para a vivência de outrem, fazendo-o refletir e posicionar-se em relação ao caso posto. Nesse sentido, como recorda Nussbaum, las obras literárias invitan a los lectores a ponerse em el lugar de personas muy diversas y a adquirir sus experiências.

Joana Aguiar e Silva (2001, p.130-31) enfatiza o papel da literatura inclusive como fomento à racionalidade emocional e empática que orienta os juristas a bem se posicionarem quando diante de questões difíceis:

[...] diz então respeito à necessidade de fomentar nos membros da comunidade jurídica aquela racionalidade emocional e empática de que se reclama uma mais justa percepção das necessidades próprias de todos e de cada um; uma razão prática de cuja importância hoje se tem plena consciência, enquanto motor fundamental de uma cabal concretização do normativo intrasistemático do ordenamento jurídico nas exigências igualmente normativas de uma prática judicativamente mediada. Uma prática em que assume um relevo constitutivo o princípio hermenêutico da applicatio. Mergulhar em hábitos de leitura, ou, ainda melhor, em mais cuidadas análises literárias, pode 
contribuir para dotar o jurista destas alternativas formas de racionalidade, apurando a sua capacidade imaginativa e a sua inteligência empática. O conhecimento dos mundos alternativos proporcionado pela ficção, o contacto por esta estimulado com situações complexas, em que é fomentada a identificação do leitor com as personagens envolvidas, tudo isso constitui um ágio para o jurista que, ao longo da sua vida profissional, terá, muito provavelmente, que enfrentar delicadas questões éticas para as quais não encontrará resposta nem nos códigos nem nos manuais.

Conforme Arnaldo Sampaio de Moraes Godoy (2011, p.13): “A literatura permite que a discussão de problemas jurídicos tome os mais inesperados caminhos. Cria-se campo interdisciplinar no qual se engendra crítica cultural muito expressiva" Da mesma forma, para Germano Schwartz (2006, p.18):

[...] a relação entre Direito e Literatura aparece como uma forma diversa de abordagem da ciência do Direito, calcada na superação do modelo heteropoiético/positivista, procurando novas formas de observação transdisciplinares (observação de segundo grau) que possibilitem a constatação e a superação do já referido distanciamento temporal para com a sociedade na qual se insere.

Como exemplos, pode-se citar a abordagem da questão agrária com a leitura do livro "Morte e Vida Severina" de João Cabral de Melo Neto; o acesso efetivo à justiça com "O processo" de Franz Kafka; a contraposição entre as correntes jusnaturalista e positivista no "Caso dos Exploradores de Caverna" de Lon Fuller; e a psicopatologia forense em "O Alienista" de Machado de Assis.

Cinema e literatura, assim, podem ser poderosos instrumentos para formação crítica dos alunos e percepção das contradições humanas manifestadas nos mais diversos temas. A frieza do estudo das leis, da doutrina e da jurisprudência cede passagem a um mundo novo, permeado de emoções, gestos, dramatizações, gritos, sorrisos, lágrimas, dores, emoções, realidades e fantasias, possibilitando que ocorra maior empatia entre o aluno e os temas a serem tratados.

Existindo empatia, ou seja, colocando-se o aluno no lugar do outro, como possibilita o cinema e a literatura, mais fácil será para ele compreender de forma adequada a importância que seus posicionamentos jurídicos têm na vida em sociedade e a necessidade de que sejam fundamentados em juízos críticos bem elaborados. De mero depositário de informações, passa o aluno a ser também agente do conhecimento, interpretando, analisando, debatendo, decidindo fatos que lhe foram apresentados de forma crua e emanados de um material artístico produzido por pessoas não necessariamente ligadas ao meio jurídico. 


\section{CONCLUSÃO}

A situação de policrise que afeta a contemporaneidade instiga a busca constante de ferramentas que possam contê-la. Constatado que o ensino do Direito não está imune a esse estado de crise disseminado, não resta outra alternativa aos juristas que buscar trilhar novos caminhos que possam atenuá-lo.

Nesse contex to, o presente artigo tratou especificamente da crise operacional do ensino jurídico oferecendo como possibilidade de melhoria de sua qualidade, a utilização da arte, notadamente o Cinema e a Literatura. Não se trata obviamente de uma solução definitiva que deva ser isolada das demais alternativas existentes. O que não se pode é permitir a manutenção de um ensino jurídico que esteja cada vez mais voltado a meramente possibilitar uma promissora carreira profissional, independentemente da adequada formação de juristas a fim de que sejam verdadeiros agentes transformadores da realidade social.

Um país tão desigual como o Brasil necessita de Bacharéis em Direito conscientes da importância da Ciência Jurídica para redução das desigualdades e para a realização da justiça social. A leitura de leis, doutrina e jurisprudência, por si só, não consegue formar juristas com tal consciência crítica. São necessárias ferramentas outras que consigam transportar os alunos para a realidade vivida pelo outro, para que sintam e percebam a vida de forma plena e não reducionista.

Importante ressaltar que um ensino que construa uma relação pedagógica participativa exige que o professor não apenas domine o conteúdo, mas que realize o planejamento das aulas utilizando estratégias adequadas a essa nova perspectiva, aos objetivos do curso e de cada aula em específico. Isso traz um ritmo diferente à docência, não mais centrada na exposição unilateral dos conteúdos, mas em técnicas que privilegiam a participação e construção próprias dos alunos.

O Cinema e a Literatura, quando utilizados de forma adequada, de acordo com as peculiaridades da turma, do horário, da disciplina e do assunto específico a ser tratado, podem ser poderosos instrumentos de sensibilização dos alunos para questões de extrema importância para a vida em sociedade pela via da empatia. Tendo contato com a realidade do outro, mesmo que pela arte, os alunos introjetam racionalidades, sensações e percepções dificilmente possíveis de serem ministradas pelo professor através do método didático-pedagógico clássico, baseado na leitura de obras jurídicas e na sua exposição. 


\section{REFERÊNCIAS}

ASSASSINATO em Primeiro Grau. Dirigido por: Marc Rocco. EUA: Warner Bross, 1994. 1 DVD.

COLAÇO, Thais Luzia. Ensino do Direito e capacitação docente. In: COLAÇO, Thais Luzia (org.). Aprendendo a ensinar direito o Direito. Florianópolis: OAB/SC Editora, 2006. p. 1334.

CUNHA, Paulo Ferreira da. Burocracia Científica e Pluralismo Cultural. Revista Internacional d'Humanitats. CEMOrOc-Feusp, Universidad Autònoma de Barcelona, n. 24, jan-abr, 2012. p. 05-16.

DIRCE, Guilherm; DINIZ Debora; ZICKER, Fabio. Pelas lentes do cinema: bioética e ética em pesquisa. Brasília: LetrasLivres: EdUnB, 2007.

EDIPE. Enciclopédia Didática de Informação e Pesquisa Educacional. 3. ed. São Paulo: Iracema, 1987.

FREIRE, Paulo. Pedagogia do Oprimido. 17 ed. Rio de Janeiro: Paz e Terra, 1987.

GHIRARDI, José Garcez. O Destino e o Caminho: Apontamentos para a Elaboração de Programas no Ensino Jurídico. In: FEFERBAUM, Marina; GHIRARDI, José Garcez (org). Ensino do Direito para um Mundo em Transformação. São Paulo: Fundação Getulio Vargas, 2012. p. 63-71.

GODOY, Arnaldo Sampaio de Moraes. Direito, Literatura e Cinema: Inventário de Possibilidades. São Paulo: Quartier Latin, 2011.

HUNT, Lynn. A Invenção dos Direitos Humanos: uma História. São Paulo: Companhia das Letras, 2009.

LACERDA, Gabriel. Direito no cinema: relato de uma experiência didática no campo do Direito. Rio de Janeiro: FGV, 2007.

LYRA FILHO, Roberto. Por que estudar direito, hoje? In: SOUSA JUNIOR, José Geraldo de. (Org.) O direito achado na rua. Brasília: Editora UnB, 1988.

MORAIS, Regis de. Cinema: a realidade de uma quimera. Campinas, SP: Editora Alínea, 2010.

MORIN, Edgar. Terra-Pátria. Porto Alegre: Sulina, 2011.

A Cabeça bem-feita: repensar a reforma, reformar o pensamento, $8^{\mathrm{a}} \mathrm{ed}$. Rio de Janeiro: Bertrand Brasil, 2003.

RODRIGUES, Horácio Wanderlei. Pensando o ensino do direito no século XXI: diretrizes curriculares, projeto pedagógico e outras questões pertinentes. Florianópolis: Fundação Boiteux, 2005. 
RODRIGUES, Horácio Wanderlei. Planejando Atividades de Ensino-Aprendizagem para Cursos de Direito. In: RODRIGUES, Horácio Wanderlei; ARRUDA JR., Edmundo de (orgs). Educação Jurídica. 3 ed. Florianópolis: FUNJAB, 2014. p. 364-386.

SCHWARTZ, Germano. A Constituição, a Literatura e o Direito. Porto Alegre: Livraria do Advogado, 2006.

SILVA, Joana Aguiar e. A Prática Judiciária entre Direito e Literatura. Coimbra: Livraria Almedina, 2001.

WARAT, Luis Alberto. Introdução geral ao direito. O direito não estudado pela teoria jurídica moderna. Porto Alegre: Safe, 1997. 